\title{
FENOLOGIA E PRODUÇÃO DA CULTIVAR TETRAPLÓIDE DE UVA DE MESA NIABELL SOBRE DIFERENTES PORTA-ENXERTOS ${ }^{(1)}$
}

\author{
MÁRIO JOSÉ PEDRO JÚNIOR ${ }^{(2,3)}$; JOSÉ LUIZ HERNANDES ${ }^{(2)}$; PEDRO LUÍS GUARDIA ABRAMIDES ${ }^{(2)}$; \\ CELSO VALDEVINO POMMER ${ }^{(2)}$; JOSÉ RICARDO MACEDO PEZZOPANE(2)
}

\begin{abstract}
RESUMO
Em experimento realizado em Jundiaí, SP, município produtor de uvas de mesa, foram estudadas, em 1999, 2000 e 2001, as combinações da cultivar-copa Niabell sobre três porta-enxertos: IAC 572 'Jales', IAC 766 'Campinas' e 'Ripária do Traviú'. Foram avaliadas: fenologia das plantas; produção das videiras e massa dos cachos, em experimento com delineamento de blocos ao acaso com 8 repetições, instalado em vinhedo conduzido no sistema de espaldeira, no espaçamento de $2 \times 1 \mathrm{~m}$. A duração do período podacolheita variou entre 138 e 144 dias. Em média, a produção da 'Niabell' não foi influenciada pelos porta-enxertos 'IAC 766' (2.213 g/planta), 'Ripária do Traviú'(2.171 g/planta) e IAC 572 (2.021 g/planta). A massa dos cachos foi superior quando 'Niabell' foi enxertada sobre 'IAC 766' $(235,9 \mathrm{~g})$.
\end{abstract}

Palavras-chave: Vitis spp., uva de mesa, variedade, massa do cacho, duração do ciclo.

\section{PHENOLOGY AND YIELD OF 'NIABELL’ TABLE GRAPE GRAFTED \\ ON THREE ROOTSTOCKS}

\begin{abstract}
Combinations of the table grape cultivar 'Niabell' grafted on three rootstocks (IAC 572 'Jales', IAC 766 'Campinas' and 'Riparia do Traviú') were evaluated in a trial conducted at Jundiaí (São Paulo State, Brazil). Data on grape plant phenology, yield and cluster weight were obtained using a randomized block design ( 3 treatments, 8 blocks and 3 plants/plot) during the years of 1999, 2000 and 2001. The experiment was installed in a trellis system, trained vineyard with wires and plants in a row spacing of $2 \mathrm{x}$ $1 \mathrm{~m}$. The duration of the phenological phase pruning-harvest lasted from 138 to 144 days. The average values of grape yield obtained for 'Niabell' grafted on 'IAC 766', 'Ripária do Traviú' and 'IAC 572' were, respectively, 2213, 2171 and $2013 \mathrm{~g} /$ plant. Cluster weight was higher for 'Niabell' grafted on 'IAC 766' $(235,9 \mathrm{~g})$.
\end{abstract}

Key words: table grape, cultivar, rootstocks, Vitis spp, phenology.

$\left({ }^{1}\right)$ Recebido para publicação em 13 de maio de 2005 e aceito em $1 .^{\circ}$ de fevereiro de 2006.

$\left.{ }^{2}\right)$ Instituto Agronômico (IAC/APTA/SAA), Caixa Postal 28, 13001-970 Campinas (SP). E-mail: mpedro@iac.sp.gov.br, jlhernandes@iac.sp.gov.br, pedro@iac.sp.gov.br,rpezzo@iac.sp.gov.br.

$\left({ }^{3}\right)$ Bolsista do CNPq. 


\section{INTRODUÇÃO}

No Estado de São Paulo, a grande maioria das uvas produzidas $(99,2 \%)$, tem como objetivo o mercado de frutas frescas. O cultivo para mesa próximo à capital, tem como cultivar predominante a Niagara Rosada, estando os produtores concentrados nos municípios de Jundiaí, Louveira, Vinhedo, Itupeva, Indaiatuba e Porto Feliz (CORRÊA e Boliani, 2001).

Atualmente, tem aumentado a demanda por cultivares de uva que possam servir como nova alternativa para o mercado consumidor que busca constantemente diferentes opções de uva de mesa. A videira 'Niabell', em avaliação realizada por Ferri (1994), visando à caracterização agronômica e fenológica de cultivares mantidas no banco de germoplasma do Instituto Agronômico, em Campinas, mostrou-se promissora como uva de mesa, em virtude das boas características e precocidade em relação à 'Niagara Rosada'.

A utilização de porta-enxertos, prática obrigatória aos viticultores devido à praga de solo conhecida como filoxera, tem sido muito estudada visando à determinação da combinação ideal entre porta-enxertos e variedades copa.

Dentre os porta-enxertos, os mais utilizados na região de Jundiaí têm sido: 'Ripária do Traviú'; IAC 572 'Jales' e IAC 766 'Campinas'. A avaliação de cultivares copa utilizando diferentes porta-enxertos foi feita para a 'Niagara Rosada' em diferentes regiões do Estado de São Paulo (Terra et al., 1987; Pauletto et al., 2001a) e no sul de Minas Gerais (Alvarenga et al., 2002); para uvas de vinho (GONÇALVEs et al., 1999; Pires et al., 1989; Terra et al., 1990); para suco (TERrA et al., 1994) e para outras cultivares de uva de mesa (SAntos Neto et al., 1976; Martins et al., 1981).

Porém, em relação à cultivar Niabell existe pouca informação quanto a combinação copa/portaenxertos, motivo pelo qual foi desenvolvido o estudo visando comparar a duração das fases fenológicas, produção e massa do cacho dessa variedade, cultivada em espaldeira, sobre os porta-enxertos: 'Ripária do Traviú'; IAC 572 'Jales' e IAC 766 'Campinas', na região produtora de uva de mesa de Jundiaí.

\section{MATERIAL E MÉTODOS}

O experimento com a cultivar Niabell, conduzida em espaldeira e cordão esporonado simples, no espaçamento de $2 \times 1 \mathrm{~m}$, foi instalado em Jundiaí (Latitude: $23^{\circ} 06^{\prime}$ Sul; Longitude: $46^{\circ} 55^{`} \mathrm{~W}$ e altitude: $715 \mathrm{~m}$ ), em área experimental do Instituto Agronômico (IAC/APTA/SAA), Campinas. Os resultados foram obtidos com as videiras em produção plena nas safras de 1999, 2000 e 2001. O delineamento experimental adotado foi o de blocos ao acaso, com três tratamentos (porta-enxertos: Ripária do Traviú, IAC 766 e IAC 572), em oito repetições, com parcelas de seis plantas tendo sido observadas as três plantas centrais.

A cultivar Niabell é uma tetraplóide obtida na Califórnia, do cruzamento entre Campbell Early tetraplóide e Niagara tetraplóide. Pelas suas características, foi lançada como variedade para plantios comerciais limitados e para chácaras e quintais, e introduzida pelo IAC, na Coleção de Cultivares em 1988, destacando-se pela precocidade, com ciclo, em média dez dias, mais curto que Niagara Rosada.

A planta é de grande vigor e sua tolerância às doenças é semelhante à da Niagara. Os cachos são de tamanho médio, compactos, cônicos e alados; as bagas são rosado-escuras, ovais e grandes, e o sabor 'foxado' é muito agradável, possui duas a três sementes grandes. Apesar dessas qualidades, tem o defeito do fácil desbagoamento, sendo seu comércio restrito à região de produção (FERRI, 1994; POMMER et al., 2003).

Os porta-enxertos utilizados no ensaio foram: IAC 572 'Jales': vigoroso, de folhas resistentes às principais moléstias, ramos que lignificam tardiamente e dificilmente perdem as folhas, ótimo enraizamento e pegamento (Pereira e Leitão Filho, 1973); IAC 766 'Campinas': vigoroso, com perfeita adaptação às condições ambientais paulistas, folhas bastante resistentes às doenças (PEREIRA e Leitão Filho, 1973) e 'Ripária do Traviú': introduzido como $V$. riparia em Jundiaí, de bom desenvolvimento, porém sem muito vigor, suscetível à antracnose, necessitando de tratos fitossanitários durante o desenvolvimento vegetativo (Pommer et al., 2003).

Semanalmente, foram efetuadas avaliações do estádio fenológico em cada repetição utilizando escala de notas que variava de 0 (gema dormente) a 17 (colheita) segundo PEDRo JúnIOR et al.(1989).

A produção (g/planta) e a massa dos cachos (g) de 'Niabell' sobre os diferentes porta-enxertos foram avaliadas colhendo-se parceladamente as uvas quando completaram sua maturação, com teor de sólidos solúveis ao redor de $15^{\circ}$ Brix. Posteriormente, foram feitas análises de variância de cada característica estudada e as médias comparadas pelo teste de Tukey, a 5\% de probabilidade. 


\section{RESULTADOS E DISCUSSÃO}

Os valores obtidos da duração dos subperíodos fenológicos e do ciclo total da videira 'Niabell' são mostrados na tabela 1. Ressalte-se que durante as avaliações, por meio da escala de notas de estádio fenológico, não foram observadas diferenças em função dos diferentes porta-enxertos utilizados. Portanto, os resultados correspondem aos valores médios para a 'Niabell'.

As diferenças observadas na duração dos subperíodos fenológicos, comparando-se os diferentes anos agrícolas foram decorrentes, principalmente, da ocorrência de temperaturas médias (Figura 1) com valores inferiores em $1,2{ }^{\circ} \mathrm{C}$, em 1999 em relação a 2000 e de $0,9^{\circ} \mathrm{C}$ em relação a 2001, no período compreendido entre a poda e a colheita. Em 2000, a ocorrência de temperaturas, em média, superiores a 1999 e a 2001, induziu as videiras a um encurtamento do ciclo em 6 a 8 dias.

A duração do subperíodo poda-brotação foi, em média, de 15 dias para as podas efetuadas durante agosto. Da brotação até o florescimento foram necessários 35 a 38 dias, enquanto do florescimento ao estádio de grão de ervilha a duração foi de 16 dias. Foi observado que, em média, o subperíodo grão de ervilha a grão verde durou 19 dias. Após o estádio de grão verde, as bagas não cresceram mais e iniciaram o processo de acúmulo de sólidos solúveis com duração de 29 a 34 dias até o início da maturação. Esse período, iniciando-se com o amolecimento das bagas e troca de cor até a colheita durou cerca de 20 a 23 dias.

A duração do ciclo total da 'Niabell' foi de 144,138 e 140 dias, respectivamente, para 1999, 2000 e 2001. Esses valores são similares aos obtidos por FERRI (1994), para essa cultivar, cuja duração do período poda-colheita foi de 146 e 152 dias durante os anos agrícolas de 1991/92 e 1993/94, na região de Jundiaí.

Os resultados de produção obtidos para a cultivar Niabell sobre os porta-enxertos: IAC 572, IAC 766 e Ripária do Traviú, para as diferentes safras, são mostrados na tabela 2. O coeficiente de variação dos valores de produção foi de $23 \%$ e não foi encontrada diferença significativa na comparação das médias de produção entre os diferentes porta-enxertos. A produção média por planta variou entre 2.021 a 2.213 $\mathrm{g} /$ planta.

Tem-se observado nos porta-enxertos 'Ripária do Traviú' e 'IAC 766' certa superioridade em termos de produção, que é relatada por diversos autores para diferentes cultivares de uva de mesa. O comportamento de 'Patrícia', sobre cinco portaenxertos, foi estudado em experimento plantado em Jundiaí, com observações ao longo de seis anos (Martins et al., 1981). Os autores destacaram que as maiores produções de uva foram obtidas sobre os porta-enxertos IAC 766 e Ripária do Traviú.

Pauletto et al.(2001a) verificaram em 'Niágara Rosada', avaliada no período de 1990 a 1998, no Vale do Paraíba, em Taubaté (SP), produções maiores quando enxertada sobre o porta-enxertos 'IAC 766' (2,59 kg/planta), em comparação ao 'Ripária do Traviú' (1,99 kg/ planta) e outros porta-enxertos.

No sul de Minas Gerais, Alvarenga et al.(2002), avaliando a produção da 'Niagara Rosada' sobre diferentes porta-enxertos, verificaram em 'IAC 766 ' e 'IAC 572' as maiores produções, cerca de 2,61 $\mathrm{kg}$ / planta, enquanto a 'Ripária do Traviú' foi de 1,87 $\mathrm{kg} /$ planta.

Tabela 1. Duração, em dias, dos subperíodos fenológicos para a uva de mesa cultivar Niabell, em Jundiaí (SP), para diferentes anos agrícolas

\begin{tabular}{lccc}
\hline Subperíodo fenológico & 1999 & 2000 & 2001 \\
\cline { 2 - 4 } & & (dias) & 15 \\
Poda - brotação & 15 & 39 & 14 \\
Brotação - florescimento & 39 & 15 & 36 \\
Florescimento - grão de ervilha & 18 & 20 & 15 \\
Grão de ervilha - grão verde & 17 & 29 & 34 \\
Grão verde - início da maturação & 32 & 20 & 23 \\
Início da maturação - colheita & 23 & 138 & 140 \\
Poda - colheita & 144 & & \\
\hline
\end{tabular}




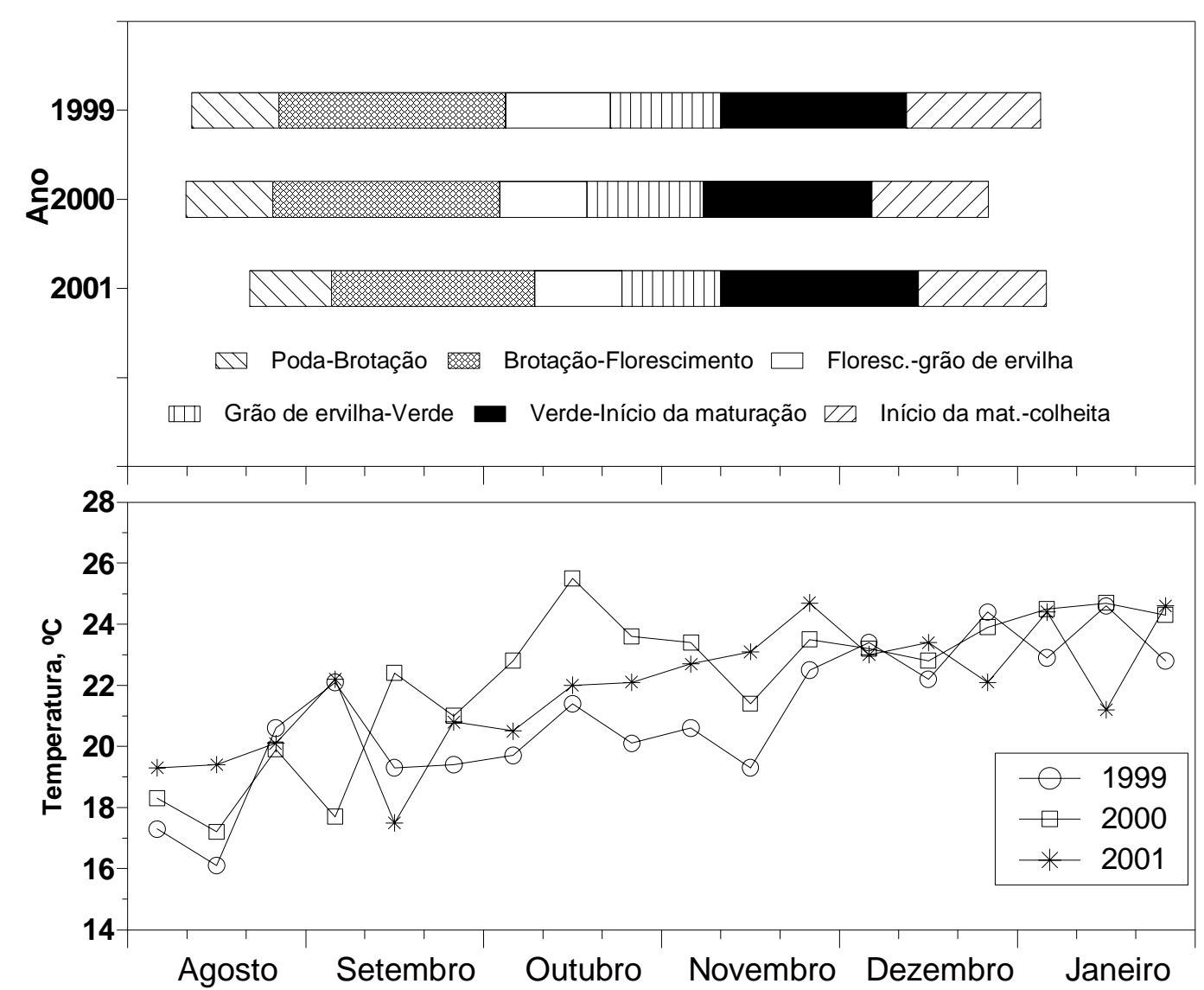

Figura 1. Subperíodos fenológicos da videira 'Niabell' e valores decendiais de temperatura média do ar em Jundiaí (SP).

Tabela 2. Produção (g/planta) da videira 'Niabell' enxertada sobre diferentes porta-enxertos, em Jundiaí (SP), para diferentes anos agrícolas

\begin{tabular}{lccc}
\hline Ano & IAC 766 & Ripária do Traviú & IAC 572 \\
\hline 1999 & 2087 & 1975 & 1725 \\
2000 & 2075 & 2162 & 1875 \\
2001 & 2475 & 2375 & 2462 \\
\hline Média & 2213 a & 2171 a & 2021 a \\
\hline
\end{tabular}

Médias seguidas da mesma letra não diferem entre si pelo teste de Tukey ao nível de 5\%. CV=23\%. DMS=463.

Em relação à massa dos cachos foi observado efeito significativo, quando da comparação dos diferentes porta-enxertos avaliados $(\mathrm{P}=0,0095)$. Pelo teste de Tukey verificou-se que o porta-enxertos 'IAC $766^{\prime}$, com valor médio de $235,9 \mathrm{~g}$, destacou-se de 'Ripária do Traviú' e 'IAC 572', com valores médios, respectivamente, de 194,0 e 196,7g (Tabela 3).

A influência do porta-enxerto sobre a massa dos cachos foi analisada para diferentes cultivares de uva. TERRA et al. (1987) avaliaram a relação de vários porta-enxertos sobre a massa dos cachos de 'Niagara Rosada', durante o período de 1975 a 1983, em Jundiaí.
Verificaram que a massa média dos cachos foi: 'Ripária do Traviú '-175g; IAC 766' - 171g e IAC 572' - 168g.

Pauletto et al. (2001b), avaliando a massa dos cachos de 'Niagara Rosada' enxertada em cinco portaenxertos, verificaram que, dentre os materiais utilizados, destacaram-se o 'IAC 766' e 'Ripária do Traviú', respectivamente, com valores médios de 195 e 168g. Por outro lado, Alvarenga et al. (2002), no sul de Minas Gerais, observaram que a 'Niagara Rosada' enxertada em 'IAC 572' foi a que proporcionou maiores cachos (193g) em comparação à 'IAC 766' com 142 g e ‘Ripária do Traviú' com 122 g. 
Tabela 3. Massa dos cachos (g) da videira 'Niabell' enxertada sobre diferente porta-enxertos, em Jundiaí (SP), para diferentes anos agrícolas

\begin{tabular}{lccr}
\hline Ano & IAC 766 & Ripária do Traviú & IAC 572 \\
\hline 1999 & 233,8 & 208,2 & 194,3 \\
2000 & 236,5 & 203,3 & 197,7 \\
2001 & 237,3 & 170,6 & 198,1 \\
\hline Média & 235,9 a & $194,0 \mathrm{~b}$ & $196,7 \mathrm{~b}$ \\
\hline
\end{tabular}

Médias seguidas da mesma letra não diferem entre si pelo teste de Tukey ao nível de 5\%. CV=15,7\%. DMS = 34,2

Apesar de ter sido notada tendência ao desbagoamento da 'Niabell", diante dos resultados de produção obtidos, aliados às características do produto, essa cultivar pode ser utilizada na região, como alternativa de uva de mesa, utilizando-se os porta-enxertos IAC 766 e Ripária do Traviú.

\section{CONCLUSÕES}

1) A duração do ciclo total, desde a poda até a colheita para a cultivar Niabell, em Jundiaí, foi pouco influenciada pelo ano e variou de 138 a 144 dias;

2) O porta-enxerto não influenciou a produção, porém sobre 'IAC 766' foram produzidos cachos de massa maior do que sobre ‘Ripária do Traviú' e 'IAC 572'.

\section{REFERÊNCIAS}

ALVARENGA, A.A.; REGINA, M.A.; FRAGUAS, J.C.; SILVA, A.L.; SOUZA, C.M.; CANÇADO, G.M.A.; FREITAS, G.F. Indicação de porta-enxertos de videiras para o sul de Minas Gerais. In: VITICULTURA E ENOLOGIA: ATUALIZANDO CONCEITOS. Caldas, 2002. p.243-256.

CORRÊA, L.S.; BOLIANI, A.C. O cultivo de uvas de mesa no Brasil e no mundo e sua importância econômica. In: SIMPÓSIO BRASILEIRO SOBRE UVAS DE MESA. BOLIANI, A.C. ; CORRÊA, L.S. (Ed.). Anais...Ilha Solteira, 2001. p.1-20.

FERRI, C.P. Caracterização agronômica e fenologia de cultivares e clones de videira (Vitis spp) mantidos no Instituto Agronômico, Campinas, SP. 1994, 89 f. Dissertação (Mestrado em Fitotecnia), ESALQ-USP, Piracicaba.

GONÇALVES, C.A.A.: REGINA, M. A.; CHAULFUN, N.N.J.; ALVARENGA, A.A.; ABRAHÃO, E.; BERZOTI, E. Comportamento da cultivar Folha de Figo (Vitis labrusca L.) sobre diferentes porta-enxerto de videira. Revista Brasileira de Fruticultura, Jaboticabal, v. 21, n. 1, p.7-11, 1999.
MARTINS, F. P.; SCARANARI, H. J.; TERRA, M. M.; IGUE, T. ; PEREIRA, F. M. Valor comparativo de cinco porta-enxertos para a cultivar de uva de mesa Patrícia (IAC 871-41). In: CONGRESSO BRASILEIRO DE FRUTICULTURA, 6., 1981, Recife, Anais...Recife: Sociedade Brasileira de Fruticultura, 1981. v. 4 , p. 1300-1310.

PAULETTO, D.; MOURÃO FILHO, F.A.A.; KLUGE, R.A.; SCARPARE FILHO, J. A. Produção e vigor da videira 'Niagara Rosada' relacionados com o porta-enxerto. Pesquisa Agropecuária Brasileira, Brasília, v.36, n.1, p.115-121, 2001a.

PAULETTO, D.; MOURÃO FILHO, F.A.A.; KLUGE, R.A.; SCARPARE FILHO, J. A. Efeito do porta-enxerto na qualidade do cacho da videira 'Niagara Rosada'. Pesquisa Agropecuária Brasileira, Brasília, v.36, n.7, p.935-939, 2001 b.

PEDRO JÚNIOR, M.J.; RIBEIRO, I.J.A.; POMMER, C.V.; MARTINS, F.P. Caracterização de estádios fenológicos da videira 'Niagara Rosada'. In: CONGRESSO BRASILEIRO DE FRUTICULTURA, 10., 1989, Fortaleza. Anais... Fortaleza: Sociedade Brasileira de Fruticultura, 1989. v.2, p. 453-456.

PEREIRA, F. M.; LEITÃO FILHO, H. F. Caracterização botânica de porta-enxertos de videira. Campinas: Instituto Agronômico, 1973. 19p. (Boletim técnico, 7)

PIRES, E.J.P.; MARTINS, F. P.; TERRA, M. M.; SILVA, A. C. P.; POMMER, C. V.; PASSOS, I. R. S.; COELHO, S. M. B. M.; RIBEIRO, I. J. A. Comportamento dos cultivares do IAC 11631 e IAC 960-12 de uva branca para vinho sobre diferentes porta-enxertos. In: CONGRESSO BRASILEIRO DE FRUTICULTURA, 10., 1989, Fortaleza. Anais... Fortaleza: Sociedade Brasileira de Fruticultura, 1989. v.2, p. 457-461.

POMMER,C.V.; TERRA,M.M.; PIRES, E.J.P. Cultivares de videira. In: Pommer, C.V. (Ed.) Uva: tecnologia de produção, pós-colheita, mercado. Porto Alegre: Cinco Continentes, 2003. p.109-152.

SANTOS NETO, J. R. A. Patrícia e Piratininga, variedades de uvas finas de mesa para climas tropicais. Bragantia, Campinas, v.35,p. CIXIX-CXXIII, 1976. (Nota, 24) 
TERRA, M.M.; PIRES, E.J.P.; POMMER, C.V.; PASSOS, I.R.S.; MARTINS, F.P.; RIBEIRO, I.J.A. Comportamento de portaenxertos para cultivar de uva de mesa Niagara Rosada em Jundiaí, SP. In: CONGRESSO BRASILEIRO DE FRUTICUlTURA, 9., 1987, Campinas. Anais...Campinas: Sociedade Brasileira de Fruticultura, 1988. v. 2, p.721-725.

TERRA, M. M.; PIRES, E. J. P; PETTINELLI JÚNIOR, A.; POMMER, C. V.; SABINO, J. C.; PASSOS, J. R. S.; COELHO, S. M. B. M.; SILVA, A. C. P.; RIBEIRO, I. J. A. Produtividade de alguns cultivares IAC de uvas para vinho como produtores diretos e sobre diferentes porta- enxertos. Bragantia, Campinas, v.49, n.2, p.363-369, 1990.
TERRA, M.M.; POMMER, C.V.; PIRES, E.J.P; RIBEIRO, I.J.A.; GALLO, P.B.; PASSOS, J. R. S. Produtividade de cultivares de uvas para suco sobre diferentes porta- enxertos IAC em Mococa, SP. In: CONGRESSO BRASILEIRO DE FRUTICULTURA, 8., 1994, Salvador. Resumos...Cruz das Almas: Sociedade Brasileira de Fruticultura, 1994. v. 3, p. 956957. 